\title{
The electrochemical behaviour of CuZn under conditions of illumination
}

\author{
Amy L. Rudd, Carmel B. Breslin * \\ Department of Chemistry, National University of Ireland Maynooth, Maynooth, Co. Kildare, Ireland
}

Received 15 December 1999; received in revised form 14 April 2000

\begin{abstract}
The influence of UV illumination on the passive behaviour of $\mathrm{Cu} 37 \mathrm{Zn}$ in $\mathrm{pH} 9.2$ and 13.0 chloride-containing electrolytes was studied using potentiodynamic polarisation tests, cyclic voltammetry and complex impedance spectroscopy. It was found that UV illumination exerted a slight activating effect on the passive behaviour in the alkaline $\mathrm{pH} 13.0$ solution, with slightly higher passive current densities being recorded under conditions of illumination. A more pronounced UV illumination effect was observed in the $\mathrm{pH} 9.2$ solution. This was characterised by a 4-fold increase in the passive current density, a shift in the breakdown potential by $250 \mathrm{mV}$ in the active direction, a decrease in the charge transfer resistance and an increase in the double layer capacitance. These results are explained in terms of the nature of the passive film on $\mathrm{CuZn}$, which consists of a complex layer involving $\mathrm{ZnO} \cdot x \mathrm{H}_{2} \mathrm{O}$ and $\mathrm{Cu}_{2} \mathrm{O} / \mathrm{CuO}$. On illumination, photo-decomposition of the n-type $\mathrm{ZnO}$ phase occurs leading to a modification of the passive layer rendering it more susceptible to pitting attack in the chloride environments. (C) 2000 Elsevier Science Ltd. All rights reserved.
\end{abstract}

Keywords: Photo-decomposition; Illumination; CuZn; Impedance; Passive film; Pitting

\section{Introduction}

The electrochemical behaviour of pure copper and zinc and the formation of copper and zinc oxides, in alkaline and slightly alkaline solutions, have been studied extensively [1-5]. It is well known that passive films formed on pure copper consist generally of a duplex structure with an inner $\mathrm{Cu}_{2} \mathrm{O}$ and an outer $\mathrm{CuO}$ layer, or hydrated $\mathrm{CuO}$ layer, with the composition of the phases being dependent on the solution composition and polarisation conditions $[1-3,6,7]$. Pure $\mathrm{Cu}_{2} \mathrm{O}$ is a p-type semiconductor with a band-gap energy of 2.2 $\mathrm{eV}$, while $\mathrm{CuO}$ also exhibits p-type conductivity [8]. It has been shown that the semiconducting properties of

\footnotetext{
* Corresponding author. Tel.: + 353-1-7083770; fax: + 3531-7083815.

E-mail address: cb.breslin@may.ie (C.B. Breslin).
}

the passive layers grown on copper depend critically on the manner in which the passive films are formed, with both p-type and n-type conductivity being reported [9-12]. On the other hand, it has been shown that the passive layers formed on pure zinc possess many properties similar to that of the non-stoichiometric $\mathrm{ZnO}$ $[12,13]$, which is an n-type semiconductor with a large optical bandgap energy of approximately $3.2 \mathrm{eV}[14,15]$.

Most of the studies conducted on the electrochemical behaviour of $\mathrm{Cu}-\mathrm{Zn}$ alloys have centred on stress corrosion cracking and dezincification [16-18]. However, it has also been shown, using electrochemical and surface analytical techniques, that the passive layers formed on $\mathrm{CuZn}$ in neutral and alkaline solutions consist of a complex combination of $\mathrm{ZnO} \cdot x \mathrm{H}_{2} \mathrm{O}$ and $\mathrm{CuO}_{2} / \mathrm{CuO}$ phases $[19,20]$.

There have been reports that irradiation of the passive films formed on zinc, copper and copper-nickel 
alloys causes changes in the passive behaviour of the electrodes [21-29]. For example, Kruger [21] showed that illumination of a copper surface in water with white light reduced considerably the rate of formation of $\mathrm{Cu}_{2} \mathrm{O}$. Chagas et al. [22], on measuring the weight loss of copper in $\mathrm{H}_{2} \mathrm{SO}_{4}$ solutions, found that the weight loss of copper was higher under conditions of illumination. Bertocci [23], using impedance measurements on bulk $\mathrm{Cu}_{2} \mathrm{O}$, showed that the charge transfer resistance decreased considerably on illumination of the electrode. In other reports, it has been shown that illumination of $\mathrm{Cu}-\mathrm{Ni}$ alloys renders the passive layers more resistant to the onset of localised attack $[24,25]$. In the case of pure zinc, it has been shown that illumination leads to an increase in the corrosion rate in chloride-containing solutions [26,27] and in alkaline solutions $[28,29]$. However, there have been no reports on the effects of irradiation on the passivity of $\mathrm{CuZn}$ alloys.

In this communication, the results of an investigation into the influence of UV illumination on the passive behaviour of $\mathrm{CuZn}$ in alkaline and slightly alkaline solutions are presented.

\section{Experimental}

Test specimens were prepared from Cu37Zn (total impurities $<6000 \mathrm{ppm}$ ). The electrodes were embedded in epoxy resins in a Teflon holder and electrical contact achieved by means of a copper wire threaded into the base of the metal sample. The exposed surfaces were polished to a 1200-grit finish using $\mathrm{SiC}$ paper. They were then cleaned in distilled water and dried under a stream of air.

The electrochemical cell consisted of a three-electrode Teflon cell with a quartz window in the base to allow irradiation of the test electrodes. A saturated calomel electrode (SCE) was used as the reference electrode and high-density graphite rods were used as the auxiliary electrodes. All potentials quoted are on the SCE scale.

The electrolytes were prepared using analytical grade reagents and distilled water. Two electrolytes were used, a borate buffer, pH 9.2 electrolyte $(0.001 \mathrm{M} \mathrm{NaOH}$, $\left.0.025 \mathrm{M} \mathrm{Na}_{2} \mathrm{~B}_{4} \mathrm{O}_{7}\right)$ and a $\mathrm{pH} 13.0$ electrolyte $(0.1 \mathrm{M}$ $\mathrm{NaOH}, 0.025 \mathrm{M} \mathrm{Na}_{2} \mathrm{~B}_{4} \mathrm{O}_{7}$ ). In the case of the chloridecontaining solutions $0.025 \mathrm{M} \mathrm{NaCl}$ was added to these electrolytes.

The illumination source was a $300 \mathrm{~W}$ xenon arc lamp (Oriel Model 6258). The light was passed through a water cooler to remove infrared radiation. The beam was then passed through a series of filters, lens and mirrors and focused on the stage to illuminate the entire surface of exposed electrode. The intensity of the light was measured as $250 \mathrm{~mW} \mathrm{~cm}$ cor $^{-2}$ for polychromatic irradiation (200-900 nm) using a Spectra-Physics CW
Laser Power Meter Model 407A. A maximum temperature rise of $1.9^{\circ} \mathrm{C}$ was recorded over an 1800 -s illumination period with this polychromatic illumination procedure.

Potentiodynamic electrochemical experiments were carried out using an EG\&G Potentiostat, Model 263. In potentiodynamic tests, the electrodes were polarised cathodically for $360 \mathrm{~s}$ to ensure any air-formed oxides were removed, and then polarised in the anodic direction at a rate of $0.5 \mathrm{mV} \mathrm{s}^{-1}$. In cases, where a pre-formed oxide was used, the electrode was immersed in the non-chloride containing electrolyte, pre-reduced and then subjected to a potential in the passive region for a set length of time. These electrodes were then transferred to the appropriate chloride-containing solution and polarised from the corrosion potential at a scan rate of $0.5 \mathrm{mV} \mathrm{s}^{-1}$ in the anodic direction. Cyclic voltammetry measurements were performed at a scan rate of $50 \mathrm{mV} \mathrm{s}^{-1}$. Impedance spectra were recorded at some applied potential, using an excitation voltage of $10 \mathrm{mV}$, using a Solartron 1250 FRA and 1287 potentiostat. All impedance data were fit to appropriate equivalent circuits using a complex non-linear least squares fitting routine, using both the real and imaginary components of the data.

\section{Results}

In Figs. 1 and 2 representative anodic polarisation plots are shown for $\mathrm{CuZn}$ polarised under various conditions of illumination and non-illumination in the chloride-containing $\mathrm{pH} 13.0$ and 9.2 electrolytes, respectively. The data presented in Fig. 1a were obtained by polarising the electrode, following a pre-reduction step in the dark at $-1.0 \mathrm{~V}$, under continuous dark conditions and continuous illumination conditions in the chloride-containing $\mathrm{pH} 13.0$ electrolyte. The data recorded in the dark were characterised by an anodic oxidation peak at $-400 \mathrm{mV}$, which corresponded to the formation of $\mathrm{Cu}(\mathrm{I})$ oxide, and a second oxidation peak at $-120 \mathrm{mV}$ which was associated with the formation of the $\mathrm{Cu}(\mathrm{II})$ oxide phase. At potentials between -100 and $+600 \mathrm{mV}$ a pseudo passive region was observed, while at potentials greater than +650 $\mathrm{mV}$ complete breakdown of the passive layer occurred. Similar features, although not identical, were seen under illumination conditions. The greatest difference between the illuminated and non-illuminated experiments lies in the magnitude of the pseudo-passive current density. For example, at $0.2 \mathrm{~V}$, the current density recorded in the dark was typically $200 \mu \mathrm{A} \mathrm{cm}{ }^{-2}$, whereas under illumination it ranged from about 290 to $380 \mu \mathrm{A} \mathrm{cm}^{-2}$. However, this photo-induced increase in the current density was not observed if the electrode was first subjected to an oxide formation step in the 
absence of illumination. This can be seen clearly from the data presented in Fig. 1b where anodic polarisation plots recorded under continuous dark and illumination conditions are shown for electrodes first polarised for 2 $\mathrm{h}$ in the chloride-free $\mathrm{pH} 13.0$ solution at $0.2 \mathrm{~V}$. In this case, essentially identical plots are recorded in both cases and the oxidation peaks associated with the formation of the two copper oxides are obviously absent.

In Fig. 2a and b, similar data recorded in the chloride-containing $\mathrm{pH} 9.2$ solution are shown. The data presented in Fig. 2a were recorded under continuous illumination and dark conditions following a pre-reduction step in the chloride-containing $\mathrm{pH} 9.2$ solution. The plot recorded in the dark was characterised by a relatively low current of about $10 \mu \mathrm{A} \mathrm{cm} \mathrm{cm}^{-2}$ in the potential interval of -200 to $450 \mathrm{mV}$. The oxidation peaks associated with the formation of the $\mathrm{Cu}(\mathrm{I})$ and
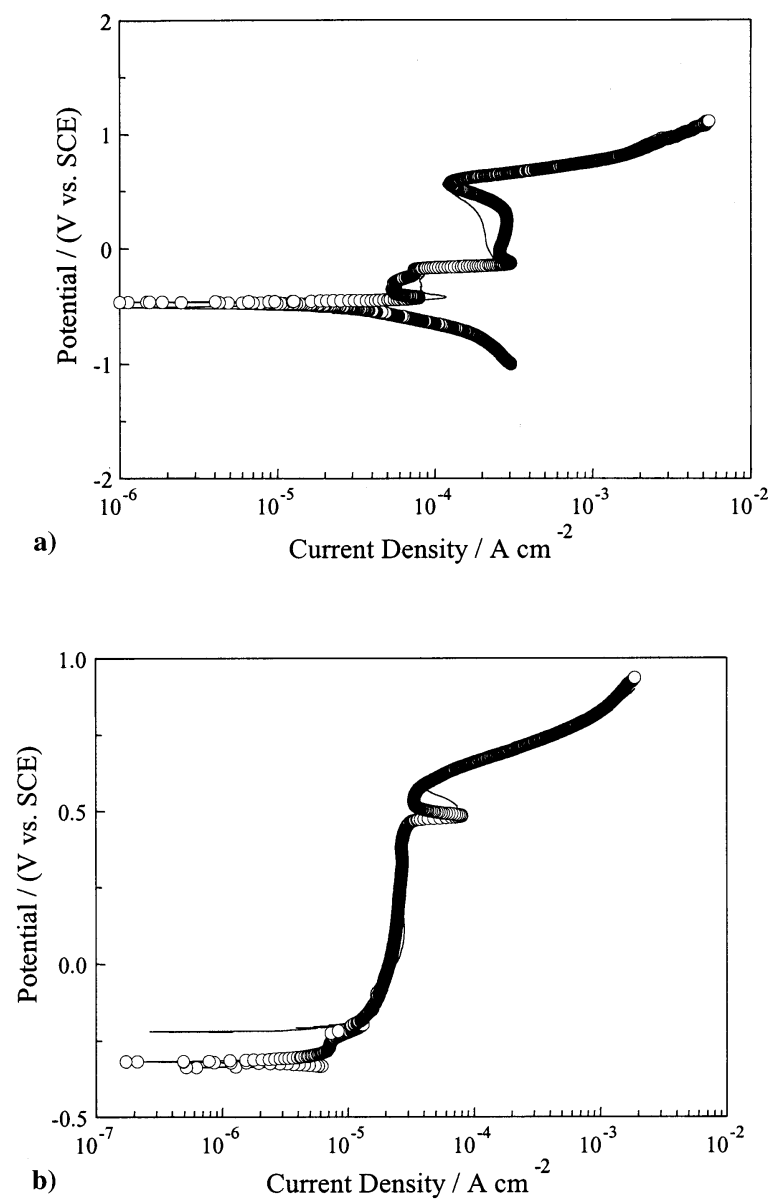

Fig. 1. (a) Anodic polarisation plots recorded in a chloridecontaining $\mathrm{pH} 13.0$ electrolyte under - dark and $\bigcirc$ illumination conditions. (b) Anodic polarisation plots recorded in a chloride-containing pH 13.0 electrolyte under — dark and $\bigcirc$ illumination conditions following a pre-oxide formation period of $2 \mathrm{~h}$ at $0.2 \mathrm{~V}$ in the chloride-free $\mathrm{pH} 13.0$ solution.
$\mathrm{Cu}$ (II) oxides were not clearly visible in this case. At potentials of approximately $820 \mathrm{mV}$, breakdown of the film occurred and this was marked by a sharp increase in the anodic current. The data recorded under continuous illumination conditions are significantly different. The anodic current density is approximately a factor of four higher, being of the order of $40 \mu \mathrm{A} \mathrm{cm} \mathrm{cm}^{-2}$ and considerably lower breakdown potentials are recorded. However, these photo-induced effects were significantly reduced if an oxide film was first formed on the electrode in the absence of chloride. Typical data, recorded under these conditions, are shown in Fig. 2b. In this case, the electrodes were first polarised in the chloridefree $\mathrm{pH} 9.2$ solution at $0.3 \mathrm{~V}$ under dark conditions for $2 \mathrm{~h}$. The electrode was then transferred to the chloride solution and polarised under continuous dark or light conditions. Here, it can be seen that the photo-induced anodic currents are smaller and that the shift in the breakdown potential on illumination is considerably smaller. Breakdown potentials recorded under dark and light conditions can be seen more clearly by the data presented in Fig. 2c. Here, cumulative probability plots of the breakdown potentials recorded under four different sets of conditions are presented. Breakdown potential data are shown for the experiments recorded under illumination conditions without a pre-oxide formation step, under illumination conditions following a pre-oxide formation step and under dark conditions without and with a pre-oxide formation step. It can be seen clearly from these data that the greatest degree of photo-induced breakdown occurs when the electrode is not subjected to a pre-passivation process. Likewise, if an oxide layer is first formed on the electrode then illumination has a much-reduced deleterious effect on the breakdown process.

In order to investigate the nature of these differing photo effects, cyclic voltammetry and photo-potential measurements were carried out in an attempt to relate the photo-effects with the nature of the passive layers formed under these solution conditions. Typical cyclic voltammograms recorded under continuous dark conditions and illumination only during the anodic scan in the chloride-free $\mathrm{pH} 13.0$ electrolyte are shown in Fig. $3 \mathrm{a}$. The electrodes were first reduced at $-1.5 \mathrm{~V}$ and then polarised at a rate of $50 \mathrm{mV} \mathrm{s}^{-1}$ in the anodic direction up to a vertex potential of $0.8 \mathrm{~V}$ and then the scan was reversed and the electrode polarised in the cathodic direction. In all, three separate reduction peaks can be distinguished and these are labelled on the diagram as Q1, Q2 and Q3. It can be seen from this plot that the current associated with the reduction of these peaks is higher under anodic illumination conditions. The ratio of the peak current densities (averaged over five measurements) recorded under illumination conditions and dark conditions, i.e. $I_{\mathrm{p}}($ illum $) / I_{\mathrm{p}}($ dark $)$ 

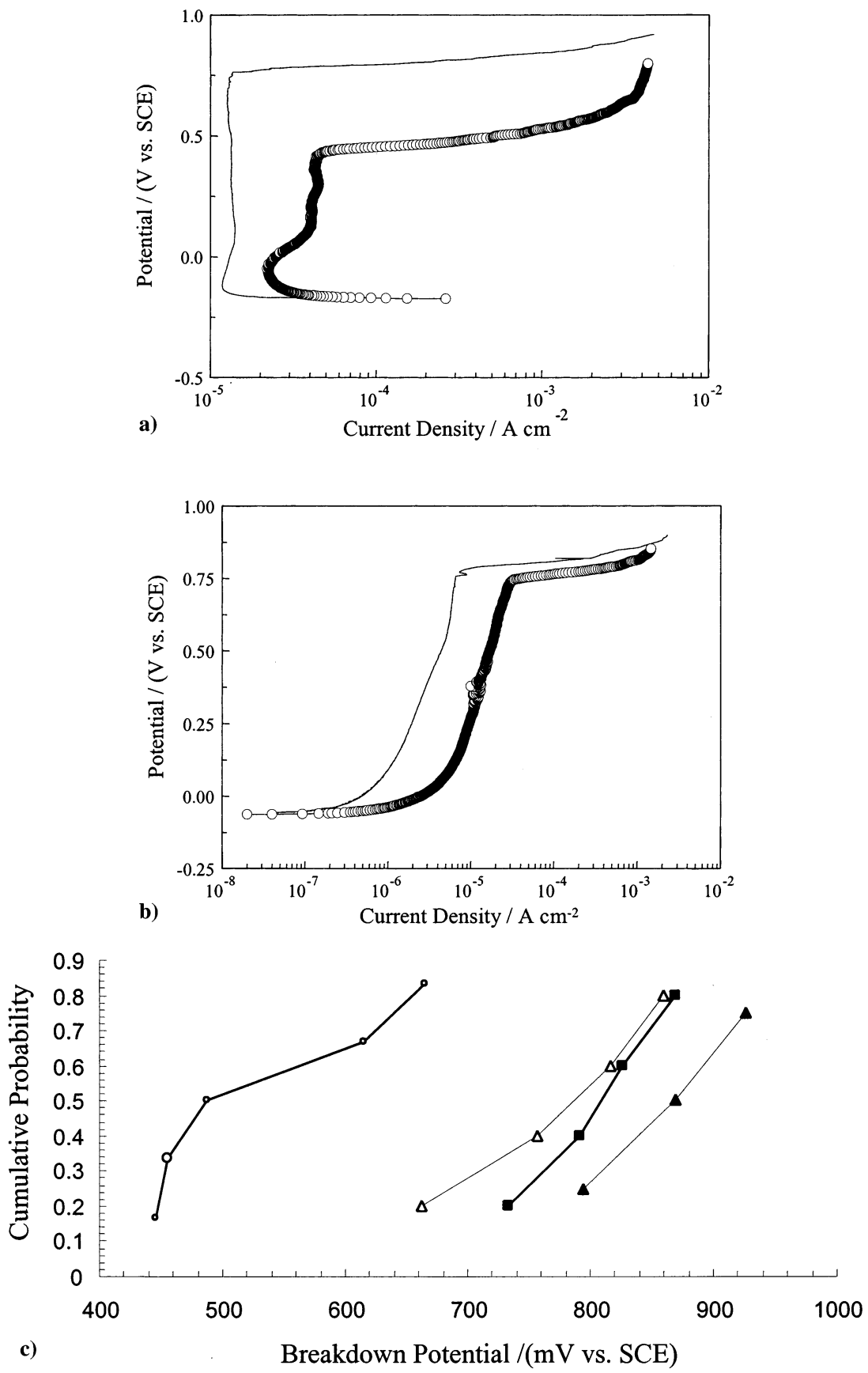

Fig. 2. (a) Anodic polarisation plots recorded in a chloride-containing pH 9.2 electrolyte under - dark and $\bigcirc$ illumination conditions. (b) Anodic polarisation plots recorded in a chloride-containing pH 9.2 electrolyte under — dark and $\bigcirc$ illumination conditions following a pre-oxide formation period of $2 \mathrm{~h}$ at $0.3 \mathrm{~V}$ in the chloride-free $\mathrm{pH} 9.2$ solution. (c) Cumulative probability plots of the breakdown potentials recorded in the $\mathrm{pH} 9.2$ solution under $\mathbf{\square}$ dark conditions, $\boldsymbol{\Delta}$ dark conditions following pre-oxide formation, $\bigcirc$ light conditions, $\triangle$ light conditions following pre-oxide formation.

for Q1 was $1.37 \pm 0.09$, while it was $1.46 \pm 0.06$ for $\mathrm{Q} 2$ and $1.38 \pm 0.02$ for $\mathrm{Q} 3$. In addition, the total reduction charge computed under dark conditions, averaged over five determinations, was $26.4 \pm 1.1 \mathrm{mC} \mathrm{cm}^{-2}$ compared with $37.1 \pm 2.3 \mathrm{mC} \mathrm{cm}^{-2}$ under illumination conditions. This was computed over the three reduction peaks using an integration routine in which zero current was taken as the baseline. 
In order to investigate whether illumination had any effect during the reductive sweep, for example a photofacilitated reduction of the oxides, as reported in the
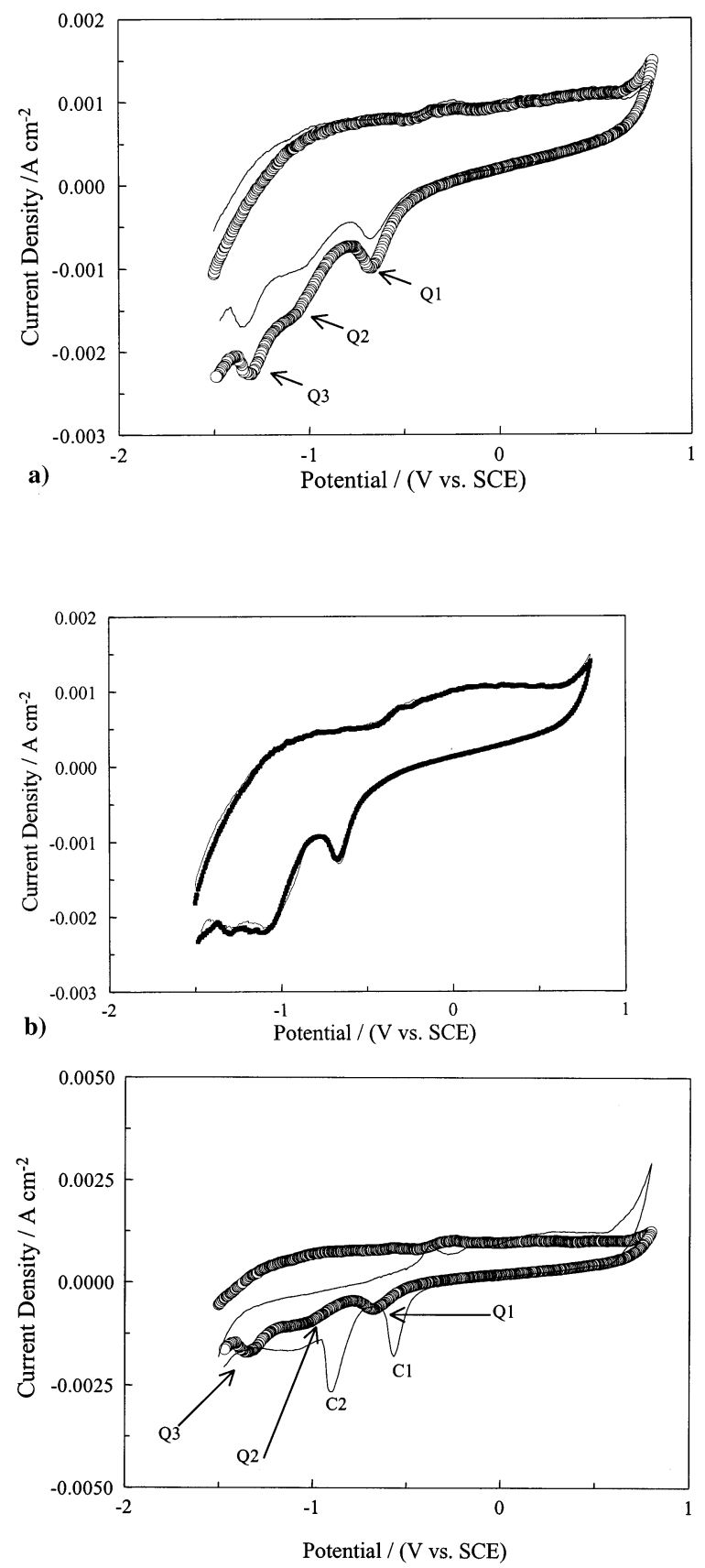

Fig. 3. (a) Cyclic voltammograms recorded in the $\mathrm{pH} 13.0$ electrolyte under - continuous dark and $\bigcirc$ anodic illumination conditions. (b) Cyclic voltammograms recorded in the $\mathrm{pH}$ 13.0 electrolyte under - continuous illumination and $\bigcirc$ illumination only during the anodic sweep. (c) Cyclic voltammograms recorded in the $\mathrm{pH} 13.0$ solution for - pure $\mathrm{Cu}$ and CuZn.

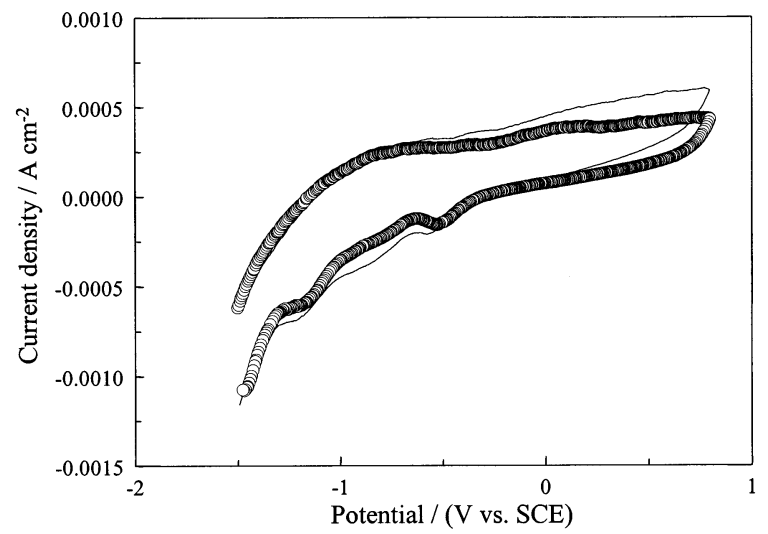

Fig. 4. Cyclic voltammograms recorded in the $\mathrm{pH} 9.2$ electrolyte for $\mathrm{CuZn}$ under - continuous dark and $\bigcirc$ continuous illumination conditions.

case of pure copper [12], a second series of experiments was carried out. The results of these tests are summarised in the data presented in Fig. 3b. Here data are shown for cyclic voltammograms recorded under continuous illumination conditions and intermittent dark conditions. These intermittent dark conditions consisted of performing the anodic scans under illumination conditions and then the surface was exposed to dark conditions during the reduction sweep. As seen from these data, essentially identical profiles are obtained under continuous illumination conditions and illumination only during the oxidative sweep, which confirms that illumination does not facilitate the reduction process in this case. Indeed voltammograms identical to those presented in Fig. 3a were obtained when the light experiments consisted of exposing the electrodes to continuous illumination conditions and the dark experiments consisted of exposing the electrode to continuous dark conditions. In Fig. 3c, the cyclic voltammograms recorded for $\mathrm{CuZn}$ and pure $\mathrm{Cu}$ in the pH 13.0 electrolyte are compared. Two clear reduction peaks $\mathrm{C} 1$ and $\mathrm{C} 2$ are seen in the case of pure copper where $\mathrm{C} 1$ is the reduction of $\mathrm{Cu}(\mathrm{II})$ and $\mathrm{C} 2$ is the reduction of $\mathrm{Cu}(\mathrm{I})$. It can be seen that in the case of the $\mathrm{CuZn}$ system, these reduction peaks are somewhat shifted to lower potentials and are less distinct, however, it is clear that Q1 corresponds to the reduction of $\mathrm{Cu}(\mathrm{II}), \mathrm{Q} 2$ to the reduction of $\mathrm{Cu}(\mathrm{I})$ and Q3 to the reduction of $\mathrm{Zn}(\mathrm{II})$. These data are in agreement with those reported by Morales et al. [19,20], who observed a potential shift in the reduction of $\mathrm{Cu}(\mathrm{II})$ and $\mathrm{Cu}(\mathrm{I})$ for various brasses.

Typical voltammograms recorded under dark and light conditions in the chloride-free $\mathrm{pH} 9.2$ solution are shown in Fig. 4. The illumination experiments were recorded under continuous illumination, but similar data were obtained if the reduction scans were recorded 


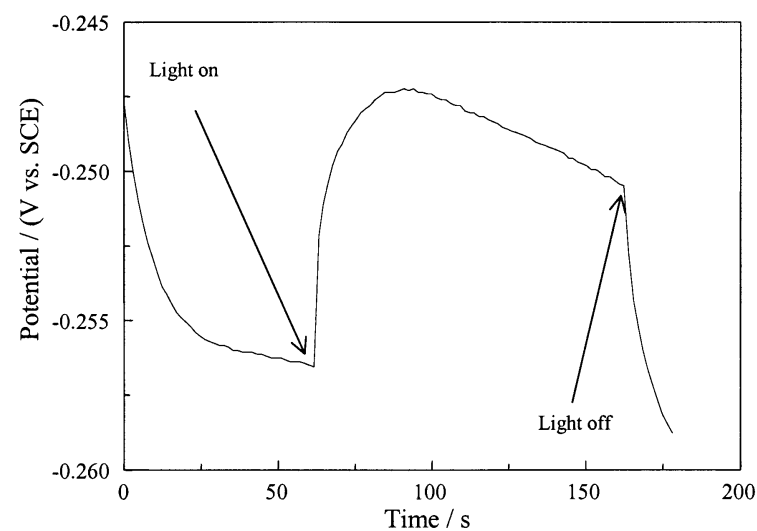

Fig. 5. Photo-potential measurement for $\mathrm{CuZn}$ in the $\mathrm{pH} 13.0$ solution.

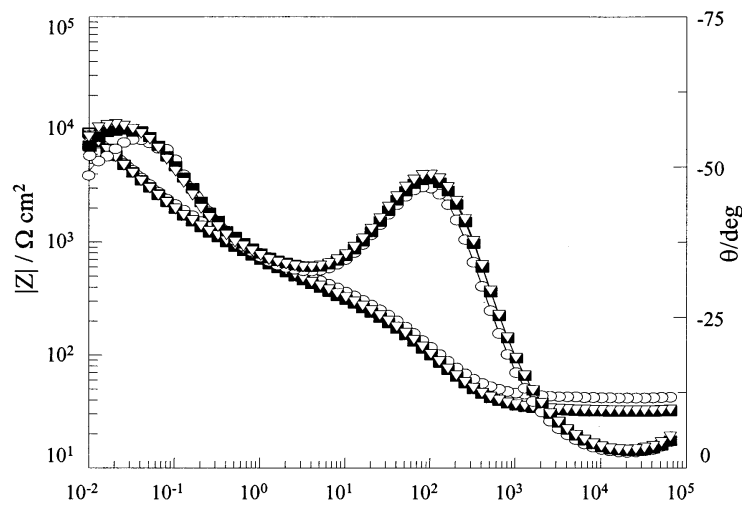

a)

Frequency $/ \mathrm{Hz}$

b)
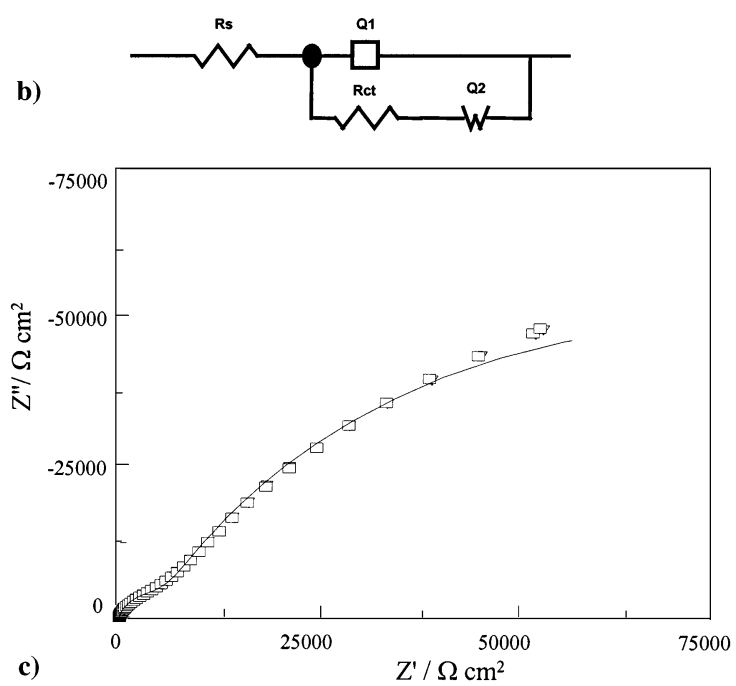

Fig. 6. (a) Impedance data recorded for $\mathrm{CuZn}$ polarised at 0.2 $\mathrm{V}$ in the $\mathrm{pH} 13.0$ electrolyte under — initial dark conditions, $\bigcirc$ illumination conditions and final dark conditions. (b) Equivalent circuit used in the fitting of the impedance data. (c) Quality of fit between experimental and simulated data. in the dark. It can be seen from a comparison of this plot with that presented in Fig. 3a that the peaks are much less defined and only the total cathodic charge could be computed. The ratio of the total cathodic charge under UV conditions and dark conditions was computed as 0.93 , averaged over five determinations. Thus, under these conditions there is no evidence to suggest photo-induced growth of the passive film. However, it can be seen on comparing the data presented in Figs. 3 and 4 that significantly higher amounts of the copper and zinc oxides are formed in the more alkaline $\mathrm{pH} 13.0$ solution. For example, the average peak current density, Q2, recorded under dark conditions was $1.50 \mathrm{~mA} \mathrm{~cm}^{-2}$ and $500 \mu \mathrm{A} \mathrm{cm}{ }^{-2}$ in the $\mathrm{pH} 13.0$ and 9.2 solutions, respectively.

A typical example of a photo-potential measurement in the $\mathrm{pH} 13.0$ solution is shown in Fig. 5. The electrode was immersed in the $\mathrm{pH} 13.0$ solution for $90 \mathrm{~min}$ and then the photo-potential was measured. The actual data shown were recorded after 90-min immersion time and were scaled to zero. The points at which the light was switched on and off were marked on the diagram. It is seen from these data that on illumination a positive photo-potential was recorded, consistent with p-type conductivity. Similar data were recorded in the $\mathrm{pH} 9.2$ solution, but the magnitude of the photo-potential was somewhat lower. Typical photo-potentials were of the order of 10 and $5 \mathrm{mV}$ in the $\mathrm{pH} 13.0$ and 9.2 solutions, respectively. It can be inferred from these data that the complex films formed on $\mathrm{CuZn}$ under these conditions behave like p-type $\mathrm{Cu}(\mathrm{I})$ and $\mathrm{Cu}(\mathrm{II})$ oxides, there is no evidence of any n-type conductivity which is seen in the case of pure zinc oxide films [28].

Impedance spectra recorded under different conditions of illumination and non-illumination are shown in Figs. 6 and 7. In Fig. 6a, typical impedance plots are shown for $\mathrm{CuZn}$ polarised at $0.2 \mathrm{~V}$ under dark and illumination conditions in the $\mathrm{pH} 13.0$ electrolyte. These data were recorded following an initial 150-min polarisation period at $0.2 \mathrm{~V}$. The impedance data were first recorded under dark conditions, then under continuous illumination conditions followed by dark conditions. These data were fit to the equivalent circuit depicted in Fig. 6b, while the fit between the simulated and experimental data could be seen from the plot shown in Fig. 6c where simulated and experimental data were compared in a Nyquist plot. The equivalent circuit consists of $R_{\mathrm{s}}$, which represents the solution resistance, $Q_{1}$ is the double layer capacitance, $R_{\mathrm{CT}}$ stands for the charge transfer resistance and $Q_{2}$, a constant phase element with an exponent close to 0.6, which represents diffusion processes. As can be seen from the presented data, illumination has little effect on the impedance response. Indeed, the fitted parameters were essentially identical for the data collected under dark and light conditions. The charge transfer resis- 


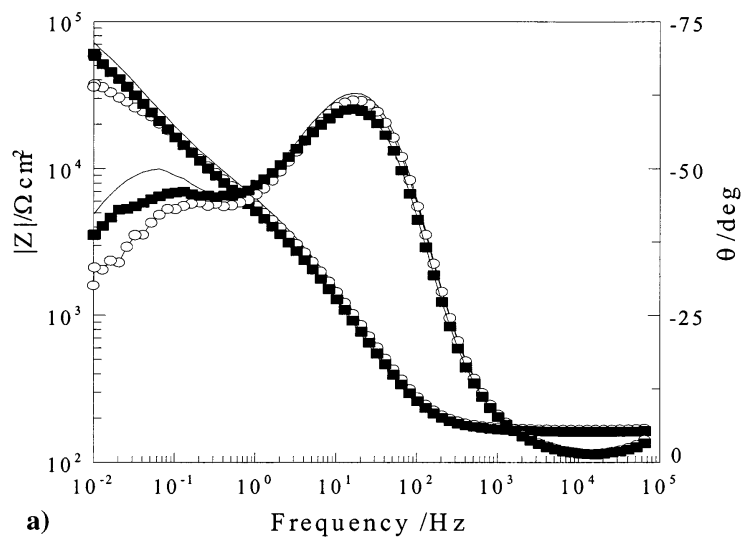

b)
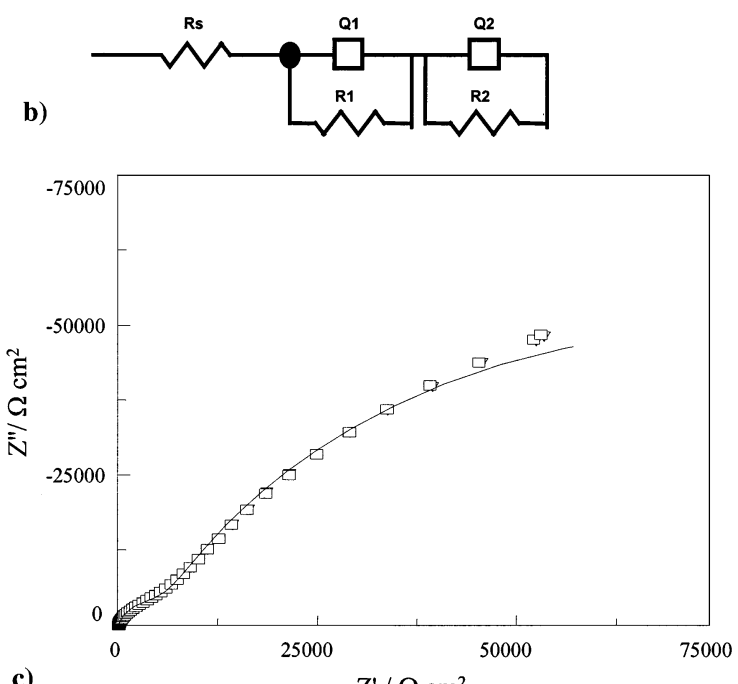

c)

$$
Z^{\prime} / \Omega \mathrm{cm}^{2}
$$

Fig. 7. (a) Impedance data recorded for $\mathrm{CuZn}$ polarised at 0.3 $\mathrm{V}$ in the $\mathrm{pH} 9.2$ electrolyte under — initial dark conditions, $\bigcirc$ illumination conditions and $\bullet$ final dark conditions. (b) Equivalent circuit used in the fitting of the impedance data. (c) Quality of fit between experimental and simulated data.

tance calculated under initial dark conditions was 400 $\Omega \mathrm{cm}^{2}$, that calculated under illumination conditions was $403 \Omega \mathrm{cm}^{2}$, while that calculated under subsequent dark conditions was $381 \Omega \mathrm{cm}^{2}$. Likewise the capaci- tance was calculated as 39,40 and $51 \mu \mathrm{F} \mathrm{cm} \mathrm{cm}^{-2}$ for dark, light and final dark conditions, respectively, while the diffusion term was computed as 566, 620 and 664 $\Omega^{-1} \mathrm{~cm}^{-2} \mathrm{~s}^{n}$ under dark, light and final dark conditions, respectively. Here, the greatest changes are seen following the illumination period, which suggests that the 40-min illumination period during the impedance measurements gives rise to some modification of the passive layer.

The impedance data recorded in the $\mathrm{pH} 9.2$ solution are presented in Fig. 7a. Again these data were recorded following a $150-\mathrm{min}$ polarisation period at 0.3 $\mathrm{V}$ and were recorded in the sequence dark, light and final dark conditions. The circuit used in the fitting of these data is shown in Fig. 7b, while the quality of the fit between the simulated and experimental data can be seen in Fig. 7c. A more complex circuit was required to fit these data and consists of two series R, Q couples. These data are dominated less by diffusion processes, compared with those presented in Fig. 6, and this is reflected in the exponents of the constant phase elements $Q_{1}$ and $Q_{2}$, which are 0.90 and 0.75 , respectively. The values of these fitted parameters are shown in Table 1 for dark, followed by dark, followed by light followed by final dark experiments. It can be seen from a comparison of the two initial dark experiments that the system is in a steady state and thus, the changes in the parameters are true illumination effects. These illumination effects are characterised by a decrease in $R_{1}$ and $R_{2}$, an increase in $Q_{1}$ and an increase in $Q_{2}$. This is consistent with a photo-induced dissolution effect. It can also be seen that the system does not revert back to its passive steady state by comparing the values of the circuit elements for the initial dark and final dark experiments. The actual significance of these circuit elements is not clear but it does seem that the $R_{1} Q_{1}$ couple may be related to the cupric/cuprous/zinc oxide passive layer, while the $R_{2} Q_{2}$ term which is more dominated by diffusion, stems from a precipitated hydroxide layer, which is dominated by zinc species. Support for this can be seen from the data presented in Fig. 8a and b. In Fig. 8a data were presented, which were recorded in the $\mathrm{pH} 9.2$ solution under similar dark conditions at $0.3 \mathrm{~V}$, but with pure copper. Here, two impedance measurements are shown, one recorded following a

Table 1

Circuit parameters for impedance data recorded under dark, followed by dark, followed by light and followed by dark conditions for $\mathrm{CuZn}$ polarised at $0.3 \mathrm{~V}$ in $\mathrm{pH} 9.2$ solution

\begin{tabular}{|c|c|c|c|c|c|c|}
\hline Condition & $R_{1}\left(\Omega \mathrm{cm}^{2}\right)$ & $R_{2}\left(\Omega \mathrm{cm}^{2}\right)$ & $Q_{1}\left(\mu \mathrm{F} \mathrm{cm}^{-2}\right)$ & $n_{1}$ & $Q_{2}\left(10^{-6} \Omega^{-1} \mathrm{~cm}^{-2} \mathrm{~s}^{n}\right)$ & $n_{2}$ \\
\hline Dark & 4627 & 142.2 & 24.7 & 0.90 & 83.1 & 0.76 \\
\hline Dark & 4636 & 144.3 & 24.8 & 0.90 & 83.5 & 0.76 \\
\hline Light & 3759 & 53.4 & 26.0 & 0.90 & 94.8 & 0.73 \\
\hline Dark & 3680 & 100.4 & 33.6 & 0.88 & 95.5 & 0.75 \\
\hline
\end{tabular}



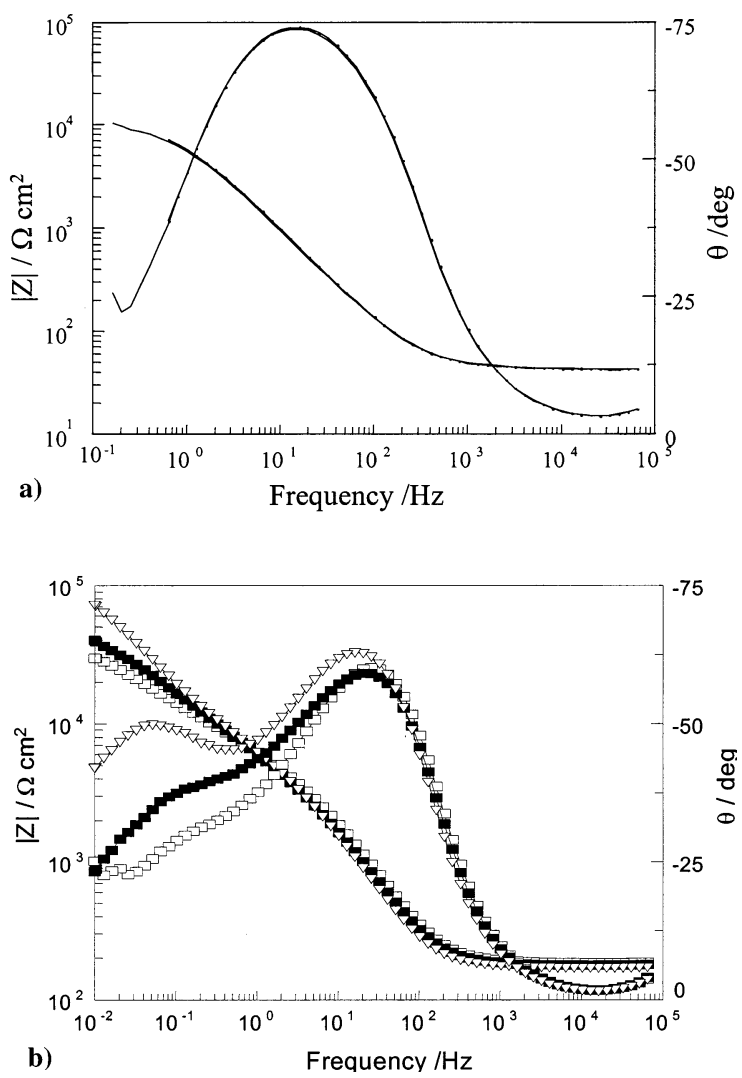

Fig. 8. (a) Impedance data recorded for pure copper polarised at $0.3 \mathrm{~V}$ in the $\mathrm{pH} 9.2$ solution. Data recorded after -180 min and after ... 240 min polarisation time. (b) Impedance data recorded as a function of the polarisation period for $\mathrm{CuZn}$ polarised at $0.3 \mathrm{~V}$ in the $\mathrm{pH} 9.2$ solution. Data recorded after $\in 3.8 \times 10^{3} \mathrm{~s}, \boldsymbol{\square} 9.8 \times 10^{3} \mathrm{~s}$ and $\triangle 98 \times 10^{3} \mathrm{~s}$.

180-min polarisation time and the second recorded following a further 60 -min polarisation period. Here, the low frequency diffusion effects are not seen. Furthermore, it is seen by comparing both scans that the system remains stable and appears to be in a true steady-state condition. In Fig. 8b, impedance spectra are shown for the $\mathrm{CuZn}$ electrode following different polarisation periods. These data were recorded under dark conditions at an applied potential of $0.3 \mathrm{~V}$ in the pH 9.2 solution after different polarisation periods of $3.8 \times 10^{3}, 9.8 \times 10^{3}$ and $98 \times 10^{3} \mathrm{~s}$. Here a clear time evolution of the data can be seen, with the low frequency diffusion region becoming more pronounced with increasing polarisation time. Thus, it seems that the low frequency diffusion region is connected with the dezincification of $\mathrm{CuZn}$ and the formation of precipitates of $\mathrm{Zn}(\mathrm{OH})_{2}$ at the surface/solution interface.

\section{Discussion}

It can be seen from these data that illumination of $\mathrm{CuZn}$ induces different effects depending on the solution composition, which in turn controls the passive layer composition. In the $\mathrm{pH} 13.0$ solution, illumination leads to only slight changes in the polarisation characteristics and in the impedance spectra. However, in the pH 9.2 solution, illumination leads to enhanced dissolution. This can be seen from the impedance data, where the charge transfer resistance is lowered on illumination of the surface. However, the greatest effect is seen in the breakdown potentials, where illumination shifts the breakdown potential by $250 \mathrm{mV}$ in the more active direction. It should be noted that these effects are not seen on polarising pure $\mathrm{Cu}$ under similar illumination conditions, but that the photo-decomposition of the passive layers on pure $\mathrm{Zn}$ is observed [28,29]. This tends to suggest that these effects are associated with the $\mathrm{ZnO}$ phase, and more precisely with the composition of the oxide layers formed on $\mathrm{CuZn}$ under these solution conditions.

Morales et al. $[19,20]$ have shown, using XPS, that the passive layer formed on various brasses in a $\mathrm{pH} 9$ borate solution consists of a complex $\mathrm{ZnO} \cdot x \mathrm{H}_{2} \mathrm{O}$ / $\mathrm{Cu}_{2} \mathrm{O}-\mathrm{CuO}$ layer. The $\mathrm{ZnO}$ electro-formation results in a dezincification process so that a thin copper-rich layer resides at the metal/oxide interface. Indeed, it could be deduced from the photo-potential data presented in Fig. 5, which were obtained following a 90-min immersion period, that the oxide layers existing under opencircuit conditions contain a relatively large amount of copper oxides. However, the outer layers will contain $\mathrm{ZnO}$ as shown by Morales et al. $[19,20]$ and the concentration of $\mathrm{ZnO}$ will be higher during the early stages of immersion. It is well known that $\mathrm{ZnO}$ is an n-type semiconductor [12-15]. On illumination with sufficiently energetic photons, electrons are promoted from the valence to the conduction band. The generated holes react with the stoichiometric $\mathrm{ZnO}$ to cause photodecomposition of the $\mathrm{ZnO}$ lattice. This sequence of events has also been shown to occur in the case of the passive films grown on zinc in alkaline solutions, in the $\mathrm{pH}$ region 13-9, where photo-decomposition of the oxide layers occurs $[28,29]$. Since the outer regions of the passive layer on $\mathrm{CuZn}$ contain $\mathrm{ZnO}$, then it is likely that UV illumination of this layer will lead to the photo-decomposition of the $\mathrm{ZnO}$ component through the reaction.

$\mathrm{ZnO}+2 \mathrm{p}^{+}+n \mathrm{OH}^{-} \rightarrow \mathrm{Zn}(\mathrm{OH})_{n}^{(2-n)}+\frac{1}{2} \mathrm{O}_{2}$

The nature of the soluble $\mathrm{Zn}(\mathrm{OH})_{n}^{(2-n)}$ species will depend on the $\mathrm{pH}$ of the solution, but in these alkaline conditions, the products are likely to be $\mathrm{Zn}(\mathrm{OH})_{4}{ }^{2-}$ or $\mathrm{Zn}(\mathrm{OH})_{3}{ }^{-}$. The above dissolution reaction is consis- 
tent with the increase in the passive current density (Fig. 1), and the increase in the capacitance and the lower charge transfer resistance values computed under illumination conditions. The lower breakdown potentials recorded under illumination conditions may be connected with an increase in the defect nature and porosity of the passive layer, brought about by the selective decomposition of $\mathrm{ZnO}$. However, this increase in the pitting susceptibility may also be connected to modifications of the protective $\mathrm{CuO} / \mathrm{Cu}_{2} \mathrm{O}$ oxide layers. The electrons generated from the electron-hole pair during illumination of the $\mathrm{ZnO}$ phase may reduce the copper oxide phase converting the $\mathrm{CuO}$ oxide to $\mathrm{Cu}_{2} \mathrm{O}$ or the $\mathrm{Cu}_{2} \mathrm{O}$ oxide to $\mathrm{Cu}$.

This photoactivation effect is seen to diminish if passive layers are first formed on the electrodes by polarisation at $0.3 \mathrm{~V}$ for extended periods (Fig. 2b). Polarisation at this potential should favour the formation of $\mathrm{Cu}(\mathrm{I})$ and $\mathrm{Cu}(\mathrm{II})$ oxides and furthermore increase the rate of dezincification leading to a greater copper-rich passive layer. Indeed the evolution of the passive layer with time can be seen from the impedance data presented in Fig. 8b. Here, the low frequency impedance is seen to increase with polarisation time, which is consistent with a dezincification process and the precipitation of hydroxide species at the oxide/solution interface. Thus, the photo-activation effect is diminished after prolonged polarisation under these potential conditions because of a decrease in the concentration of the $\mathrm{ZnO}$ semiconductor phase.

The lack of any substantial photo-effect in the $\mathrm{pH} 13.0$ solution seems to be connected also with the concentration of the $\mathrm{ZnO}$ phase in the complex passive layer. It can be seen clearly by comparing the cyclic voltammetry data in Figs. 3 and 4 that the rate of $\mathrm{Cu}(\mathrm{I})$ and $\mathrm{Cu}(\mathrm{II})$ oxide formation is considerably higher in the $\mathrm{pH} 13.0$ solution. Also under these highly alkaline $\mathrm{pH}$ conditions $\mathrm{ZnO}$ is not predicted to be the stable phase [4]. Both of these effects mean that the concentration of $\mathrm{ZnO}$ in the complex passive layer is reduced and thus illumination has only a slight activating effect on the complex passive layer.

\section{Conclusions}

A significant decrease in the breakdown potential, an increase in the passive current density and lower charge transfer resistance values were observed on illumination of $\mathrm{CuZn}$ in $\mathrm{pH} 9.2$ solutions. However, these effects were diminished, if the electrode was first subjected to an oxide formation step at $0.3 \mathrm{~V}$, before the illumination experiments. A much lower photo-activation effect was observed in the $\mathrm{pH} 13.0$ solution. These findings may be explained in terms of the photo-decomposition of $\mathrm{ZnO}$, which exists in the complex passive layers formed on $\mathrm{CuZn}$.

\section{Acknowledgements}

The authors gratefully acknowledge the support of this work by Enterprise Ireland, under the Basic Science Research Grants Award, Project Code SC/96/456.

\section{References}

[1] B. Miller, J. Electrochem. Soc. 116 (1969) 1675.

[2] L.M. Abrantes, L.M. Castillo, C. Norman, L.M. Peter, J. Electroanal. Chem. 163 (1984) 209.

[3] C.H. Pyun, S.M. Park, J. Electrochem. Soc. 133 (1986) 2040.

[4] D.D. Macdonald, K.M. Ismail, E. Sikora, J. Electrochem. Soc. 145 (1998) 3141.

[5] T.E. Graedel, J. Electrochem. Soc. 136 (1989) 193.

[6] T.D. Burleigh, Corrosion 45 (1989) 464.

[7] F. Ammeloot, C. Fiaud, E.M.M. Sutter, Electrochim. Acta 44 (1999) 2549.

[8] H.R. Schöppel, H. Gerischer, Ber. Bunsenges Phys. Chem. 77 (1973) 310.

[9] F. Di Quarto, S. Piazza, C. Sunseri, Electrochim. Acta 30 (1985) 315.

[10] E.M.M. Sutter, B. Millet, C. Fiaud, D. Lincot, J. Electroanal. Chem. 386 (1995) 101.

[11] E.M.M. Sutter, C. Fiaud, D. Lincot, Electrochim. Acta 38 (1993) 1471.

[12] J. Buchholz, Surf. Sci. 101 (1980) 146.

[13] P. Scholl, X. Shan, D. Bonham, G.A. Prentice, J. Electrochem. Soc. 138 (1991) 895.

[14] G. Heiland, E. Mollwo, F. Stockmann, Solid State Phys. 8 (1959) 191.

[15] A.K. Vigh, Electrochemistry of Metals and Semiconductors, Marcel Dekker, New York, 1973.

[16] H.W. Pickering, C. Wagner, J. Electrochem. Soc. 224 (1967) 698.

[17] R.C. Newman, T. Shahrabi, K. Sieradzki, Corros. Sci. 28 (1988) 873.

[18] J.C. Scully, Met. Sci. 12 (1978) 290.

[19] J. Morales, G.T. Fernandez, S. Gonzalez, P. Esparza, R.C. Salvarezza, A.J. Arvia, Corros. Sci. 40 (1998) 177.

[20] J. Morales, P. Esparza, G.T. Fernandez, G. Gonzalez, J.E. Garcia, J. Caceres, R.C. Salvarezza, A.J. Arvia, Corros. Sci. 37 (1995) 231.

[21] J. Kruger, J. Electrochem. Soc. 106 (1959) 847.

[22] L.V. Das Chagas, E.W. Grabner, R.S. Gonçalves, Electrochim. Acta 40 (1995) 1735.

[23] U. Bertocci, J. Electrochem. Soc. 125 (1978) 1598.

[24] C.B. Breslin, D.D. Macdonald, Electrochim. Acta 44 (1998) 643.

[25] D.D. Macdonald, H. Brookes, M. Urquidi-Macdonald, M. Vazquez, Corrosion 55 (1999) 343.

[26] E. Juzeliunas, P. Kalinauskas, A. Stankeviciute, A. Sudavicius, A. Survila, Corrosion 51 (1995) 673.

[27] P. Spathis, I. Poulios, Corros. Sci. 37 (1995) 673.

[28] A.L. Rudd, C.B. Breslin, Electrochim. Acta 45 (2000) 1571.

[29] A.L. Rudd, C.B. Breslin, J. Electrochem. Soc., 147 (2000) 1401. 